Mediterranean Journal of Humanities mjh.akdeniz.edu.tr I/ 1, 2011, 63-69

\title{
Türkçe Sözlüğe Katkılar I
}

\section{Contributions to Turkish Dictionary I}

\begin{abstract}
Ali CíN*
Özet: Eklemeli bir dil sistemine sahip olan Türkçenin zengin bir kelime yapma mekanizması vardır. Önemli olan bu zenginliğin yerinde ve doğru bir şekilde kullanılmasıdır. Türkçenin eklerinin zenginliğine ve türetme imkânının genişliğine rağmen Cumhuriyet dönemine kadar kelime türetiminin daha ziyade Arapça ve Farsça kökler ve eklere dayanan türetmelerle yapıldığını görüyoruz. Ancak bu dili kullanan halk, kullandığı dilin imkânlarından yararlanarak yeni bir takım kelimeler türetmekten hiçbir zaman vazgeçmemiştir. Ağızlarda kullanılan Türkçe kelimeler bunun en güzel kanıtıdır. Cumhuriyetten sonra bir zihniyet değişikliğiyle Arapça, Farsça kök ve eklere dayanan bu türetmeden vazgeçillerek Türkçe kök ve eklerle yeni türetmeler yapılmaya başlanmıştır. Cumhuriyetten günümüze değin yaklaşık seksen yıllık zaman diliminde kelime türetimiyle ilgili ciddi mesafe alınmıştır. Kelime türetme işi bazen bu dili kullanan halk tarafından bazen bu dilde edebî ürünler veren yazarlar, bazen bilim adamlarınca, bazen de gazeteciler tarafından yapılmıştır. Bu çalışmada bugün Türkiye Türkçesi sözlüğünde kullanılmayan ancak bazı gazetecilerimiz ve yazarlarımız tarafından kullanılan kelimeler üzerinde durulacaktır.
\end{abstract}

Anahtar Sözcükler: Kelime türetme, sözlük, kelime, yeni kelime yapma

Abstract: Turkish language is an agglutinative language which has a rich vocabulary making mechanism. It is important that this rich capacity is used of properly. Despite wide vocabulary derivation opportunities and the richness of Turkish suffixes, we see more use of derivative words in Arabic and Persian to the period of the Republic. But the people who use this language never given up language used by taking advantage of opportunities producing a new set of words. The most beautiful proof of this is Turkish words which are used in the Anatolian dialects. After the Republic with a mindset change which abandoned vocabulary derivation based on Arabic and Persian roots and attachments and with Turkish roots and attachments new derivatives started. From the Republic to the present, an approximately eighty-year time period, the derivation of the word has covered a serious distance. The work of word derivation has been made sometimes by the population who spoken this language, sometimes by authors who have given literary works in this language, and sometimes by scientists and journalists. In this study words which are not used in the dictionary of Turkey Turkish today, but are used by scientists and journalists will be mentioned.

Keywords: Word derivation, dictionary, word, making a new word

Dil, yeryüzünde bir anlaşma vasıtası olduğu günden bugüne değin sürekli yeni kelimelere ihtiyaç duymuştur. Medeniyetin gelişmesi ve toplumların yeni kültür ve dinlerle tanışması dilleri, yeni kavramları karşılayacak kelimeler türetme gibi bir gayretin içerisine sokmuştur. Her dil, ihtiyaç duyduğu kelimeleri ya kendi dilinin imkânlarından yararlanarak elde eder ya da başka dillerden alır. Eklemeli bir dil sistemine sahip olan Türkçe, bugüne değin bu özelliğini birçok kelime türeterek ortaya koymuştur. Kelime türetme işi, bazen bu dili kullanan halk, bazen bu dilde edebî ürünler veren yazarlar, bazen bilim adamlarınca bazen de gazeteciler tarafından ya-

\footnotetext{
* Yrd. Doç. Dr., Akdeniz Üniversitesi, Edebiyat Fakültesi, Türk Dili ve Edebiyatı Bölümü, Antalya, alicin@akdeniz.edu.tr
} 
pılmıştır. Bu çalışmada bugün Türkiye Türkçesi sözlüğünde kullanılmayan ancak bazı gazetecilerimiz ve yazarlarımız tarafından kullanılan kelimeler üzerinde duracağız. Bunu yaparken de yazımızda geçen örnek kelimelerde, yazarların imlasına bağlı kalınmıştır.

olumla-:/olumlan-: $(o l+u+m+l a-)$ Türkçe Sözlük'te olumlama "olumluluğu ortaya koyma, icap" kelimesi yer alırken aynı kökten olumla- ve olumlan- biçimleri yer almamaktadır. Kelime, $o l$ - fiil kökünden önce - $m$ ile fiilden isim, sonra Türkçenin isimden fiil türetme eklerinden - $l a$ ile genişletilmiş ve daha sonra da $-n$ - fiilden fiil yapma ekiyle edilgenleştirilmiştir. Aslında kelimenin kullanımı isim gövdesine - $l u$ isimden isim yapım eki getirilip daha sonra -la ekiyle isimden fiil yapım biçimiyle olumlula-, olumlulan- şeklinde de olabilirdi. Kelime her iki haliyle de Türkçenin gramer yapısına uygundur. Aşağıdaki örneklerde de görüleceği üzere olumla- kelimesi "olumlu olarak kabul etmek, olumlu görmek" anlamlarında kullanılmıştır.

"Danıştay Başsavcısı Tansel Çölaşan, bir sempozyumda konuşurken, 27 Mayıs 1960'taki askeri darbeyi, hem gerekçeleriyle, hem de sonuçlarlyla olumlayan, öven, kutlayan bir konuşma yapti”. (Emre Aköz, Sabah Gazetesi, 11.03.2008).

"Sol hesaplaşmamış, demiryollarının yabancı şirketlere büyük tazminatlar ödenerek devletleştirilmesi hep olumlanmış. Ama bugün öyle bir noktaya geldik ki yabancı sermaye gelsin diye yırtınıyoruz, gelse çok sevineceğiz". (Star Gazetesi, 24 Kasım 2009, Fadime Özkan'ın Mete Tunçay'la yaptığı röportajın ikinci bölümü...).

rüyala-: (rüya+la-) Türkçe sözlükte rüya kelimesi vardır. Ancak rüyala- biçimi yer almamaktadır. Kelime köken itibariyle (ru'yā) Arapçadır. Üzerine Türkçenin isimden fiil yapım eklerinden -la eki getirilerek farklı bir biçimde kullanılmaya başlanmıştır. Rüyala- kelimesi "rüya görmek" anlamında kullanılmıştır. Aslında Türkiye Türkçesinde rüya kelimesi göryardımcı fiiliyle yaygın bir biçimde kullanılmaktadır. Ayrıca bunun yanı sıra rüyasına gir-, rüyasında gör- tabirleri de görülmektedir. Rüyala- kelimesi Türkçenin gramer yapısına uygun bir kelimedir.

"Hiçbir koşulda hiçbir halt olmaz, ama farkında değil! Basbas bağırarak rüyalamaya devam etsin" (Perihan Maden, Radikal Gazetesi, 25.03.2008).

mahkemelen-: (mahkeme+le-n-) Arapça kökenli bir kelime olan ve Türkiye Türkçesinde mahkeme biçimiyle "yargılanmanın yapıldığı yer, mekân" anlamında zengin ve geniş bir kullanım alanına sahip olan bu kelimenin mahkemelen- şeklinde kullanıldığını gördük. Arapça bir isim olan mahkeme kelimesi Türkçenin isimden fiil yapım eklerinden -le ekiyle fiilleşmiş ve ardından $-n$ fiilden fiil ekiyle daha da genişlemiştir. Mahkemelen- kelimesi "yargılanmak" anlamında kullanılmıştır.

"Yani: Cumhurbaşkanı'nın mahkemelenmesi, cezalandırılmasıyla ilgili bir-iki kişinin itirazı olmuş ki, oy çokluğuna düşmüşler" (Perihan Mağden/Radikal, 01.04.2008).

andıçlan-: (andıç+la-n-) Türkçe Sözlükte andıçlan-, ya da andıçlanma kelimesi yer almamaktadır. Ancak andıç kelimesi "uyarı ve hatırlatmak amacıyla yazılan not" anlamıyla sözlükte yer almaktadır. Andıçlan- kelimesi andıç kelimesi üzerine önce isimden fiil yapma eki -la, daha sonrada fiilden fiil yapım eki - $n$ ile genişlemiştir. - $m a$, me fiilden isim yapma ekiyle andıçlanma biçimi ortaya çıkmıştır. Aynı gövdeden türetilmiş bu iki kelime de Türkçenin gramer yapısına uygundur. Andıçlan- kelimesi "birisi hakkında uyarı ya da hatırlatmak amacıyla not tutmak" anlamında kullanılmıştır.

"Kimse kendini andıçlanamazlar listesinde göremiyor çünkü herkes andıçlanmaya müsait" (Ergun Babahan, Sabah Gazetesi, 10.04.2008).

işlevsizleştir-: (iş+lev+siz+le-ş-tir-) Türkçe Sözlük'te, işlev, işlevci, işlevcilik, işlevsel, işlevsiz, işlevsizlik gibi aynı gövde ailesine ait sözler alırken, işlevsizleştir- biçimine rastlanılmamıştır. Kelime işlevsiz gövdesi üzerine önce -le isimden fiil yapma eki daha sonra -ş- fiilden fiil yapım eki ve daha sonra da -tir- fiilden fiil yapma ekiyle oluşmuştur. Türkçenin kelime türetme 
yapısına uygun bir kelimedir. Ayrıca kelimenin isim biçimi olan işlevsizleştirme şekli de kullanılmıştır. İşlevsizleştir- kelimesi, "işlevi olmayan duruma getirmek" anlamında kullanılmıştır.

"Maksatlı ve sistemli olmasa da, yargıya yönelik bir işlevsizleștirme çabası var. Bu, özellikle birileri böyle bir çaba içinde olduğu için değil, yargı erki kendisini tartışılır kılan kararlara imza attı̆̆ için böyle" (Ahmet Kekeç, Star Gazetesi, 22.05.2008).

rivayetlen-: (rivayet+le-n-) Arapça bir kelime olan rivayet sözcügü Türkiye Türkçesinde geniş bir kullanım alanına sahiptir. Türkçe Sözlükte rivayet kelimesi geçmektedir. Ancak rivayetlen-kelimesi geçmemektedir. Rivayetlen- kelimesi, rivayet kelimesi üzerine önce isimden fiil yapma eki -la getirilmiş daha sonra da fiilden fiil yapma eki - $n$ - getirilerek yapılmıştır. Türkçenin gramer kurallarına uygun bir kelimedir. Rivayetlen- kelimesi "rivayet etmek" anlamında kullanılmıştır.

“Vatan'dan Mustafa Mutlu'ya -zaten borçlarının 24 milyon dolar tuttuğunu- söylemiş. Ki, piyasada borçlarının 7 milyon dolar olduğu rivayetleniyormuş Özkan'ın" (Perihan Mağden, Radikal Gazetesi, 15.05.2008).

ayrımlaştır-: (ayrım+la-ş-tır-) Türkçe Sözlükte ayrım, ayrımlama, ayrımla-, ayrımlaşma, ayrımlaş- $v b$. türevleri kullanılırken ayrımlaştır- ve ayrımlaştırma biçimleri yer almamıştır. Kelime, ayrımla- fiil gövdesinden önce -ş- fiilden fiil yapım ekiyle arkasından da -tır- fiilden fiil yapım ekiyle genişletilmiştir. Ayrımlaştır- kelimesi "ayrımlı duruma getirmek" anlamında kullanılmaktadır. Ayrımlaştırma ise "Ayrımlı duruma getirme işi, farklılaştırma durumu" anlamında kullanılmaktadır.

"Bu suçlamanın kendisine dönecek bir bumerang olduğunu unutarak. Kafam, düşüncesinde özgür diyordu; vicdanım ise kınıyordu, bu ayrımlaştırmayı. Daha önce de çok yazdım, çok söyledim. Ü̧̧ alanda kin, düşmanlık, tutkunluk gibi duygulara yer yoktur: Devlet yönetimi, bilim, yargl" (Şamil Tayyar, Star Gazetesi, 17.06.2008).

büyüklenmeci: (büyük $+l e-n-m e+c i$ ) Türkçe sözlükte büyüklen- kelimesi "kendini büyük göstermek" büyüklenme kelimesi ise "kendini büyük gösterme" anlamlarında kullanılmıştır. Türkçe Sözlükte büyüklenmeci kelimesi yer almamaktadır. Kelime büyüklen- gövdesi üzerine önce -ma,me fiilden isim yapım eki sonra da $-c l$, -ci isimden isim yapma ekinin getirilmesiyle oluşturulmuştur. Büyüklenmeci kelimesi "kendini büyük görme, kibirli olma" anlamlarında kullanılmıştır.

"Bu davranışının karşıtlarında hile ve şüphe duygusunu artıracağını hesap edememişti. Siyasi hatalarında ve şüpheli ölümünde büyüklenmeci davranışlarının önemli rolü vardı" (Nevzat Tahran, Giyotinin kesmemesi mümkün mü? Zaten her hafta bir suikast...”. www.as-der.org.tr, 29 Mart 2008).

yanlılaştır-: (yan+ll+la-ş-tır-) Türkçe sözlükte yanlı "yandaş" yanlılık "yanlı olma durumu" gibi kelimeler geçerken yanlılaştır- kelimesi bulunmamaktadır. Kelime yanlı isim gövdesi üzerine la isimden fiil yapma ekinin getirilmesi, -ş- fiilden fiil yapım eki ve -tır-fiilden fiil yapım ekiyle genişletilmiştir. Kelime "taraflılaş̧ırmak, yanlı olmak" anlamlarında kullanılmıştır.

"8 Haziranda bir televizyon izlencesinde bir bilim adamımız, bir meslektaşını iktidar partisine yakınliğ ile bilinen diye sunuyor ve bilimsel kişiliğini örselemeye, onun görüşlerini de işin başında yanlılaştırmaya, güçsüzleştirmeye çabalıyordu" (Şamil Tayyar, Star Gazetesi, 17.06. 2008).

haberleștir-: (haber+le-ş-tir-) Türkçe Sözlükte haberleş- kelimesi yer alırken haberleştirbiçimi yer almamaktadır. Kelime haberleş- fiil gövdesine -tir- fiilden fiil yapım ekinin getirilmesiyle yapılmıştır. Kelime "haber yapmak" anlamında kullanılmıştır.

"Böylesine duyargaları açık yazarlara sahip gazetenin, başka Ankara Temsilcilerinin ancak bir gün sonra gazetelerinde değerlendirebildikleri iddianame metnini diğerlerinden bir gün önce 
haberleş̧irmesine hiç mi hiç şaşırmadım" (Taha Kıvanç, Yeni Şafak Gazetesi, 19.03.2008).

bütünlüklü: (bütün+lük+lü) Türkçe Sözlük’te bütünlük kelimesi "bütün olma durumu, tamamiyet" anlamlarında kullanılırken bütünlüklü kelimesi sözlükte yar almamıştır. Kelime, bütünlük isim gövdesi üzerine isimden isim yapım eki olan -lü ekinin getirilmesiyle yapılmıştır. Kelime "parçalanmamış, parçalı olmayan, bütün, tam" anlamlarında kullanılmıştır.

"Fırat'ın bu saptaması hem doğru, hem de yanlış. Çünkü toplum bütünlüklü, tek parçadan oluşan bir varlık değildir. Sinıf ve zümrelerden oluşur" (Emre Aköz, Sabah Gazetesi, 25.06. 2008).

hormonlan-: (hormon+la-n-) Hormon kelimesi, Fransızca kökenli bir kelime olup Türkçe Sözlük'te "Íç salgı bezlerinden kana geçen ve organların işlemesini düzenleyen adrenalin, insülin, tiroksin vb. uyarıcı maddelerin genel adl; bu maddelerin işlevini yerine getirecek özellikte yapay madde" anlamlarında kullanılmıştır. Hormonlan- kelimesi, hormon kelimesi üzerine önce isimden fiil yapma eki -la getirilerek daha sonra da $-n$ - fiilden fiil yapım ekinin getirilmesiyle yapılmış bir kelimedir. Hormonlan- "Bir canlının her anlamda daha çabuk gelişmesi için yapay madde vermek" anlamında kullanılmıştır.

"Ecevit koalisyonu, son anda medya ihanetine uğrayana kadar, yamanmış medya desteğiyle hormonlanabildi mi?" (Umur Talu, Sabah Gazetesi, 02.04.2009).

araçsallaştır-: (araç+sal+la-ş-tır-) Türkçe Sözlükte araçsallaştırmak kelimesine rastlanılmamıştır. Sözlükte yalnız bu kelimenin kökü olan "araç" kelimesi bulunmaktadır. Araçsallaştırmak kelimesi, üzerine önce isimden isim yapma eki + sal-getirilmiş daha sonra -la isimden fiil yapım eki daha sonra -ş- fiilden fiil yapma eki ve son olarak da -tır-fiilden fiil yapma eki getirilerek yapılmıştır. Kelimenin fiil ismi olan araçsallaştırmak biçimi son halidir. Kelime Türkçenin gramer yapısına uygun olarak yapılmıştır. Araçsallaştır- kelimesi "araç gibi kullanmak, araç görmek" anlamlarında kullanılmıştır.

"Anayasa Mahkemesi, 367 kararında olduğu gibi hukuku araçsallaş̧tırmak isteyenlerin yanında mı yer alacak, yoksa ancak hukuk yoluyla özgür ve demokratik bir ülke olacağımızın bilinciyle mi hareket edecek?" (İsmet Berkan, Radikal Gazetesi, 11.04.2008).

tümleşme: (tüm $+l e+s+m e)$ Türkçe Sözlükte tümle- kelimesi "tüm durumuna getirmek, tamamlamak" anlamında kullanılırken tümleşme kelimesine rastlanılmamıştır. Kelime tümle- fiil gövdesi üzerine -ş- fiilden fiil yapma eki ve -me fiilden isim yapma ekinin getirilmesiyle türetilmiştir. Tümleşme kelimesi "bütünleşme" anlamında kullanılmıştır.

"Varlığın, evrenin, ruhun, maddenin, yerin, göğün, yaratanın, yaratılanın özdeşleştiği buluşmanın, birleşmenin, birliğin, tümleşmenin, eriyip kaynaşmanın dile daha yetkin ve güzel yansımasını düşünmek bile olanaksız...”. (İlhan Selçuk, Cumhuriyet Gazetesi, 13.04.2008).

sınavlan-: $(\sin a+v+l a+n$-) Türkçe Sözlükte sınav kelimesi ve bu kelimenin yardımcı fiillerle kullanılan sinav vermek, sinava girmek, sinava çekilmek biçimleri yer alırken sinavlan- şekli sözlükte yer almamıştır. Eski Türkçe metinlerde sınag (sınag > sınav) biçiminde gördüğümüz bu kelime -g>-v değişmesine uğrayarak bugün sınav şeklinde kullanılmaktadır. Sınavlan- kelimesinin kullanımını "sinav olmak” anlamıyla Kemal Tahir'in eserlerinde görmekteyiz.

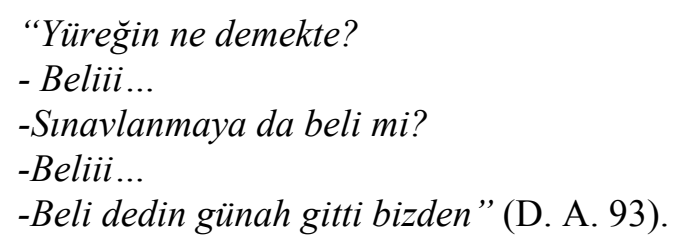

rezillen-: (rezil+le+n-) Arapça bir kelime olan rezil kelimesi Türkçenin tarihî metinlerinden günümüze değin kullanılan bir kelimedir. Ancak Türkçe Sözlükte rezillen- kelimesi bulunmamaktadır. Rezillen- kelimesi -la, -le isimden fiil yapma eki ve $-n$ - fiilden fiil yapım ekinin bir- 
leşmesinden oluşmuştur. Rezillen- kelimesi Türkçenin gramer yapısına uygundur. Kelime "rezil olmak" anlamında kullanılmıştır.

"Hele sultan rezillenirse...(D. A. 250); Sirayı şaşırıp, rezillenmek yok..." (D. A. 226).

köprüle-: (köprü+le-) Köprü kelimesi Türkçe Sözlükte yer alırken köprüle -biçimi yer almamaktadır. Köprüle- kelimesinin kullanımını Kemal Tahir'in eserlerinde "köprü yapmak" anlamıyla kullanıldığını görüyoruz.

“Gücü yetse Karasu'yu köprülemez mi?” (D. A. 583).

edepsizlen-: $(e d e b+s i z+l e-n$-)Arapça bir kelime olan edep kelimesi Türkçe Sözlükte "edep, hayâ" anlamıyla kullanılmaktadır. Edepsizlen- kelimesi ise sözlükte yer almamaktadır. Edepsizlen- kelimesi + le isimden fiil yapma eki ve - $n$ - fiilden fiil yapım ekinin birleşmesinden oluşup "edepsizlik etmek" anlamında kullanılmıştır.

“-Edepsizlendi, bu itoğlu...” (D. A 133).

vermezlen-/çıkmazlan-/duymazlan-/geçmezlen-: (ver-+mez+le-n-...) Bugün ölçünlü Türkiye Türkçesinde -maz+lan-; mez+len- yapısı ile ilgili olarak Türkçe Sözlük'te sadece bil- fiilinin kökünden bilmezlen- "bilmiyor gibi görünmek, bilmezlikten gelmek, tecahül etmek, meseleyi bilmezlemek" kelimesini görüyoruz.

Ahter-i Kebir'de tenâkür kelimesi, "bilmezlenmek, tecahül gibi" anlamlar verilerek açıklanmıştır (Ahteri, 1310).

Türkiye Türkçesinde bugün pek kullanmadığımız ancak tarihî metinlerdeki örneklerde daha çok rastladığımız -maz+lan-; mez+len- yapısının şekil itibariyle, -maz,-mez olumsuz sıfat fiil eki üzerine -la isimden fiil yapım eki ve $-n$ fiilden fiil yapım ekinin gelmesiyle oluştuğu görülmektedir.

-maz+lan-; mez+len- yapısı ile ilgili ilk bilgiyi Deny'nin (1941) Grammaire De la Langue Turque (Dialecte Osmanlı) adlı eserinde görmekteyiz. Deny, -ma-mez-lik gibi yapıları anlattıktan sonra, "işitmez görünmek" anlamında işitmezlen- fiilinin kullanıldığını söyler.

Kononov (2001), -maz+lan-; mez+len- yapısı ile ile ilgili olarak, Deny'nin (1941) verdiği bilgileri tekrar etmekle yetinir. Ergin (1993), partisipler konusunda -maz, -mez'i anlattıktan sonra, Eski Anadolu Türkçesinde ekin bugünkünden farklı bir kullanışının da bilmezlenşeklinde olduğunu ifade etmektedir.

Tarihî sözlüklerden Lehcetü'l-Lügat'ta bilmezlen- fiili, "bilinen nesneyi bilmezlenmektir" şeklinde anlamlandırılmıştır.

Ahmet Vefik Paşa'nın (2000) Lehçe-i Osmanî’sinde işitmezlen- fiili “sağırlı̆̆a vurmak, sağırlıktan gelmek, tesallüm " biçiminde anlamlandırılmıştır.

-maz+lan-; mez+len- yapısının Kemal Tahir' in Devlet Ana adlı eserinde geniş bir kullanıma sahip olduğunu görüyoruz.

"Anladım, korku yüreğine yol buldu, soluğun tıkandl, sesin çıkmazlandı". "çıkmıyormuş gibi olmak" (D. A. 388); Kızın yalvarmasına dayanamadı da vermezlendi mi? (D. A. 539) Herif koca bir sancak beyine kızı neden vermezlendi? (D. A. 262);

-Sarhoş musun Alişar Bey, sakın kulağın mı duymazlandı? (D. A. 382); Neden geçmezlenir kervan? Güven ister çünkü tüccar takımı... (D. A. 51)".

Yukarıdaki örneklerde de görüleceği üzere, vermezlen- "vermez görünmek, vermek isteyip de vermezmiş gibi görünmek"; duymazlan- "duyup da duymazlıktan gelmek"; çıkmazlan- "ses çıkarmak isteyip ama çıkarmak istemez gibi görünmek"; geçmezlen- "geçmek isteyip de geçmek istemezmiş gibi yapmak" anlamlarında kullanılmıştır.

Yukarıda üzerinde durduğumuz kelimelerin büyük bir kısmı Türkçenin isimden fiil yapma eki olan -la,-le ekiyle türetilmiş kelimelerdir. Türkçenin tarihî metinlerinde de -la, -le ekinin bu 
özelliğinden yararlanılarak türetilmiş kelimeler bulunmaktadır. Bunlardan bazıları şunlardır:

zindanla-: (zindan+la-) zindana atmak

"züleyhā aydur bu og̀lan zindānlag̀ıl

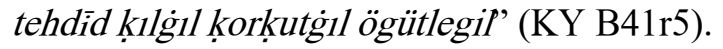

da 'valaş-: (dava+la-ş-) davalamak

“'aḳl kāmil 'ilm ü hikmet temām bilür

müdde 'ïlerda'vālaşı ana kelür'” (KY B51r6).

du 'ala-: (dua+la-) dua etmek

"du'ālamag̉a eyle āsān olsun èmdì" (KY A69v8).

zinharla-: (zinhar+la-)yasaklamak

“anlar aydur bizler seni zinharladuk" (KY B16r7).

fikirlen-: (fikir+le-n-) düşünmek

"Ben bir şey fikirlendim, söyleyeyim, ĕger ma'kul ise görün deyüb

fikirlendüği tedbiri söyleyüb dedi kim..." (GSM 52b).

pusulan-: (pusu+la-n-) pusu kurmak

Amma küffâr-1 la'in derbend içinde vâfir yaya kâfir komuş idi kim, as-

ker-i İslâm gelürse yol vermeyeler ve hattâ ol melâinler pusulanmışidi.

(GSM 22b)

sifatla-: (sifat+la-) vasiflarını bildirmek

“...bunları gah ibadet çoklugiyıla sifatlar gah hubligiyıla sifatlar gah şekilleri ulu olmagilla sifatlar' (TIKT 22a16).

sıfatlan-: (sıfat+la-n-) vasıfları belirtilmek

"bu sifatla sifatlananları severler" (TIKT 27a/21).

\section{Sonuc}

Yukarıda üzerinde durduğumuz kelimeler, bize Türkçenin mükemmel bir üretim mekanizmasının bulunduğunu ispat etmektedir. Kelime türeterek dile katkıda bulunmak sadece belirli zümrelere ait değil, toplumun bütün katmanlarında yer alan Türkçe kullanıcılarının işidir. Kelime türetmenin en doğru biçimi, Türkçe köklere dayalı olarak kelime türetmektir. Ancak modern Türkiye Türkçesinde kökeni Türkçe olmayan bazı köklerden de kelimeler türetilmiştir.

Arapça ve Farsça köklerden kelime türetmede Türkçenin isimden fiil yapım eki olan $+l a$; +le ekinden çokça istifade edilmiştir. Bunun örneklerini Türkçe Sözlük'te görmekteyiz. (ayıpla-; hastalan-; hayıflan-; rüzgarlan-...) Ayrıca bu ve buna benzer örnekler Türkçenin tarihî metinlerinde de görülmektedir.

Yukarıda Türkçenin gramer yapısına uygun, yapaylıktan uzak bir biçimde türetilen (olumla-) olumlan-; rüyala-; mahkemelen-; andıçlan-; işlevsileştir-; rivayetlen-; ayrımlaştır-; büyüklenmeci; yanlılaştır-; haberleştir-; bütünlüklü; hormonlan-; araçsallaştır-; tümleşme; sinavlan-; rezillen; köprüle-; edepsizlen-) bu kelimeler Türkçe Sözlük'te birer madde başı olarak yer alarak Türkçe kelime hazinesinin zenginleşmesine katkıda bulunabilir.

-maz+lan-; mez+len- yapısıyla ilgili olarak Türkçe Sözlükte sadece bil- fiili kökünden bilmezlen- "bilmiyor gibi görünmek, bilmezlikten gelmek, tecahül etmek, meseleyi bilmezlemek" kelimesini görüyoruz. Bu yapıyla ilgili olarak tarihî metinlerde de bu türden örnekler görülmektedir. Günümüz Türkiye Türkçesinde Kemal Tahir'in eserlerinde -maz+lan-; mez+lenyapısıyla ilgili olarak birçok örnek geçmektedir. Bu örneklerde geçen yapılar da Türkçe Sözlük'e önemli bir zenginlik katacaktır. 


\section{Kisaltmalar}

age: Adı Geçen Eser

D.A.: Devlet Ana

GSM: Gazavat-1 Sultan Murat

KY: Kissa-y1 Yusuf

TİKT: Târih-i İbn-i Kesîr Tercümesi

\section{KAYNAKÇA}

Ahmet, V. P. (2000). Lehçe-i Osmanî. Hazırlayan: Recep Toparlı, Ankara: Türk Dil Kurumu Yayınları.

Ahteri, M. (1310). Ahter-i Kebir. İstanbul: Matbaa-i Amire.

Argunşah, M. (2008). Sözüm Türkçe Üstüne. İstanbul: Kesit Yayınları.

Deny, J. (1941). Grammaire De la Langue Turque (Dialecte Osmanll). Ali Ulvi Elöve Çevirisi 1941. 1022.

Develi, H. (2008). Dil Doktoru. İstanbul: Kesit Yayınları.

Ergin, M. (1993). Türk Dilbilgisi. 318-576. İstanbul: Bayrak Yayınları.

İnalcık H., ve Oğuz, M. (1989). Gazavat-ı Sultan Murad b. Mehemmed Han. Ankara: Türk Tarih Kurumu Yayınları.

Kononov, A. H. (2001). Grammatika Sovremennogo Turetskogo Literaturnogo Yazıka. Moskova 1956. İstanbul: Multilingual Yayınları, 159.

Şeyhülislâm Mehmet Esat Efendi (1999). Lehcetü'l-Lügat. Hazırlayan: Ahmet Kırkkılıç, Ankara: Türk Dil Kurumu Yayınları.

Türkçe Sözlük (2005). Ankara: Türk Dil Kurumu Yayınları,

Türkçenin Dünü, Bugünü, Yarını, Uluslararası Bilgi Şöleni (2002). 7 Ocak 2002. Ankara: Kültür Bakanlığı Yayınları.

Yabancı Kelimelere Karşılıklar (2002). (Komisyon tarafından hazırlanmıştır) Ankara: Türk Dil Kurumu Yayınları.

Yelten, M. (1998). Tarih-i İbn-i Kesir Tercümesi. Ankara: Türk Dil Kurumu Yayınları.

Zülfikar, H. (2008). Doğru Yazma ve Konuşma Bilgileri. Ankara: Zerpa Yayınları. 